Egyptian

Orthodontic Journal

\title{
PHENOTYPIC CHARACTERIZATION OF NEW MOUSE MODEL OF CLASS III MALOCCLUSION
}

\author{
Mohamed G. Hassan ${ }^{1}$, Timothy C. Cox ${ }^{2}$, Hanan A. Ismail ${ }^{3}$, \\ Mohamed I. Mowafy ${ }^{4}$
}

\section{ABSTRACT:}

Many factors are contributing in the development of Class III malocclusion, and these factors are interacting inbetween during the craniofacial morphogenesis affecting the development and growth of nasomaxillary complex as well as the Mandible. The aim of this study was to characterize new mouse model of Class III malocclusion. Sixteen mutants (Sofa) and twelve controls were imaged by micro-computed tomography. The three dimensional models of the mice were phenotypically characterized. The mutation was expressed phenotypically in the form of midface deficiency, and anomalies in cranial sutures as well as synchondroses. Sofa mutants are likely to be used in future as model of mid face deficiency and Class III malocclusion.

\section{INTRODUCTION}

The development of craniofacial structures is considered to be highly complex, conserved, and in the same time a harmonious process that requires the migration of specialized cell populations to form five bilateral paired protrusions. Failure in the coordination and integration inbetween these processes during early stage of facial morphogenesis will lead to wide range of defects affecting the craniofacial system. So, it's important to carefully understand the development.

1- Graduate Student, Orthodontic Department, Alexandria University and Demonstrator, Orthodontic Department, Sinai University.

2- Professor, Department of Pediatrics, School of Medicine, University of Washington, USA.

3- Professor, Orthodontic Department, Alexandria University.

4- Assistant Professor, Orthodontic Department, Alexandria University.

Volume 44 - December 2013 
Class III malocclusion is considered to be one of the challenging cases that face the orthodontist in his daily practice. Many factors are contributing in the development of Class III malocclusion, and these factors are interacting in between during the craniofacial morphogenesis and affecting the development and growth of nasomaxillary complex as well as the mandible.

Class III malocclusion has been always referred to mandibular prognathism, but this comprises only one side of much larger complicated syndrome, since it does not include a single pattern. ${ }^{1}$ This syndrome may be manifested by mandibular prognathism only, maxillary deficiency, or combination of both. ${ }^{2,3}$ Over years, literature was focusing on studying mandibular prognathism as a main pattern of Class III malocclusion, however the reduction of midface prominence gives the typical appearance of concave profile. ${ }^{4-6}$ Craniosynostosis of facial sutures is one of main causes of midface hypoplasia. ${ }^{7}$ Midfacial hypoplasia represents an essential sign among signs and symptoms of syndromes characterized by craniosynostosis such as Apart and Pfeiffer syndromes. ${ }^{8}$

The aim of present work was to phenotypically characterize a spontaneous arisen mutation in new mouse model; characterized with midface deficiency that may act as future animal model of class III malocclusion.

\section{MATERIALS AND METHODS}

\section{Animals:}

A total number of 28 mice were used during the course of the study. The animals consisted of spontaneously arisen mutation mouse model (Sofa) and its non-mutant control (Table 1) generated by Jackson Laboratories Repository $\left(\mathrm{JAX}^{\circledR}\right)^{*}$. Mice aged in between 25 and 30 days were euthanized by $\mathrm{CO}_{2}$ inhalation and freezed in $-4^{\circ} \mathrm{C}$ Freezer.

\footnotetext{
* The Jackson Laboratory, 610 Main Street, Bar Harbor, Maine 04609, U.S.A. www.jax.org.
} 
The mutation has been selected according to:

1- Being arisen spontaneously and not intentionally induced.

2- The presence of midface hypoplasia.

Table 1. Sample size of mutant mice and their non-mutant controls.

\begin{tabular}{|c|c|c|c|c|c|}
\hline \multirow[b]{2}{*}{ Mutant Name / ID } & \multicolumn{2}{|c|}{$\mathbf{N}$} & \multirow[b]{2}{*}{ Background } & \multicolumn{2}{|c|}{$\mathbf{N}$} \\
\hline & 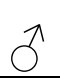 & 9 & & $\delta$ & 9 \\
\hline Short faced (Sofa) & 4 & 12 & $\mathrm{C} 57 \mathrm{BL} / 6 \mathrm{~J}$ & 12 & NA \\
\hline Total & \multicolumn{2}{|c|}{16} & & \multicolumn{2}{|c|}{12} \\
\hline
\end{tabular}

Micro-computed tomography analysis

\section{Scanning protocol}

All specimens were imaged by micro-computed tomography $(\mu \mathrm{CT})$ using a SkyScan 1076 microtomograph* at the Small Animal Tomographic Analysis Facility (SANTA) located at Seattle Children's Hospital Research Institute ${ }^{* *}$, which facilitates three-dimensional (3D) morphometric analyses via high-resolution data capture. The specimens were scanned with preciously accepted protocol 18 micron resolution (55 $\mathrm{KV}, 180 \mathrm{~mA}, 360 \mathrm{~ms}, 0.5 \mathrm{Al}$ filter). ${ }^{9}$

Image data were reconstructed using NRecon software package (Fig.1). Three-dimensional CT data model of each skull was imported into Analyze 10 software (Mayo Foundation for medical Education and Research, Rochester, MN, USA). Each specimen was subjected to trace tool to segment the skull from the vertebrae. Later, the three-dimensional model of each skull was imported into Drishti software to locate 3D volume rendering (Fig.2).

* SKYSCAN. Kartuizersweg 3B,2550 Kontich, Belgium.www.skyscan.be.

** Small Animal Tomographic Analysis Facility, Cox Lab, Centre of Cell and Tissues, Seattle Children's Research Institute.Building 1, $19009^{\text {th }}$ Avenue, Seattle, WA 98101,

USA.www.seattlechildrens.org/research/. 


\section{Egyptian}

Orthodontic Journal
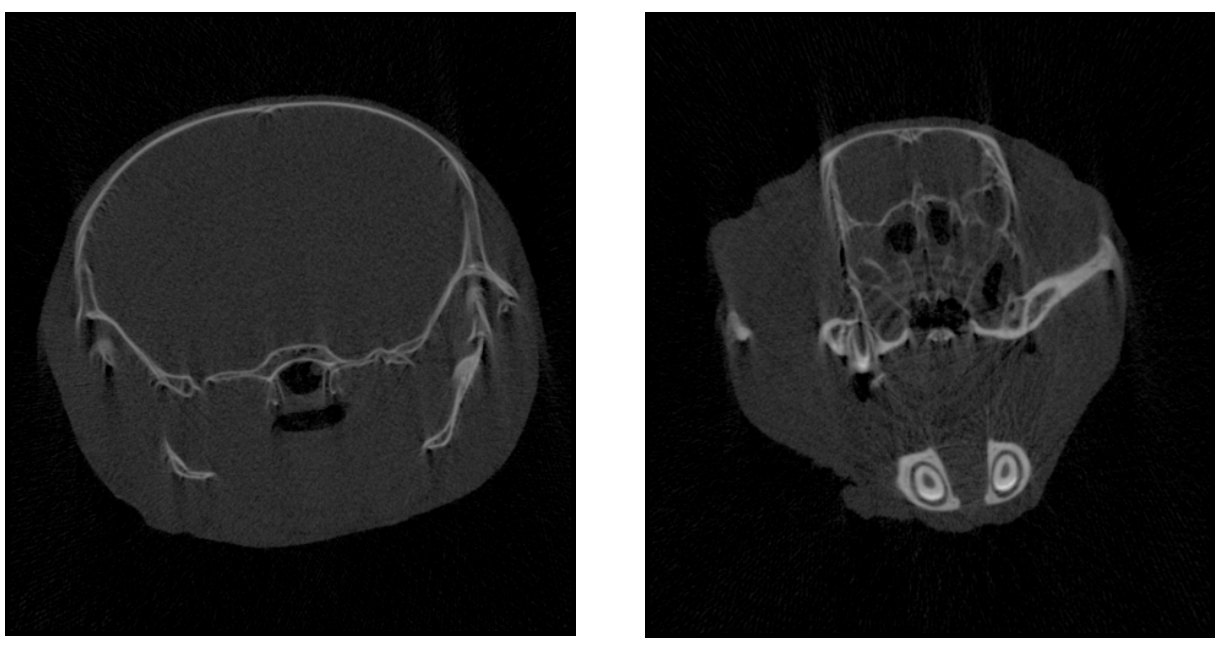

Figure 1. Reconstructed model by NRecon Software Package.

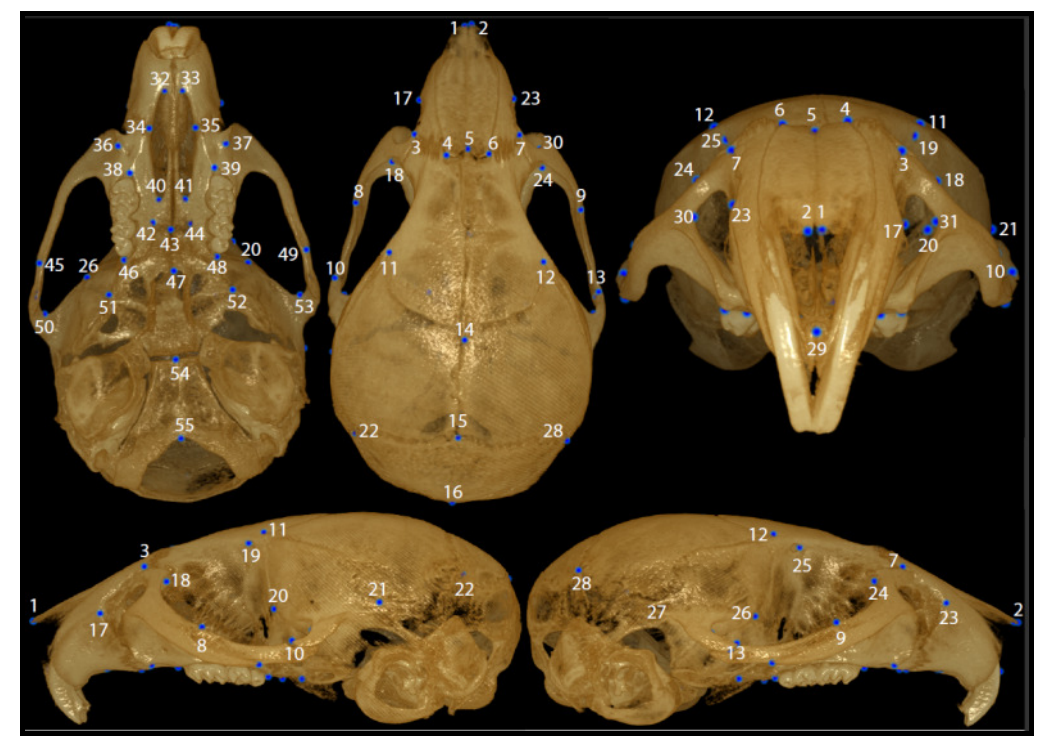

Figure 2. Three-Dimensional Model Rendered in Drishti Software. 


\section{Egyptian}

Orthodontic Journal

\section{RESULTS}

The Sofa mutation affects skull shape and is characterized by a short nose. The mice have varied penetrance ranging from an obvious to a subtler short nose phenotype. The mutation penetrance is also affecting the expression of midfacial hypoplasia. (Fig.3) Some mice exhibits normal overjet with upper molars are heading the lower molars, while other are associated with edge-to-edge relationship with lower molars in front of upper molars and an increase in facial height. Anterior crossbite was not seen in any Sofa mutants. (Fig.3-4)

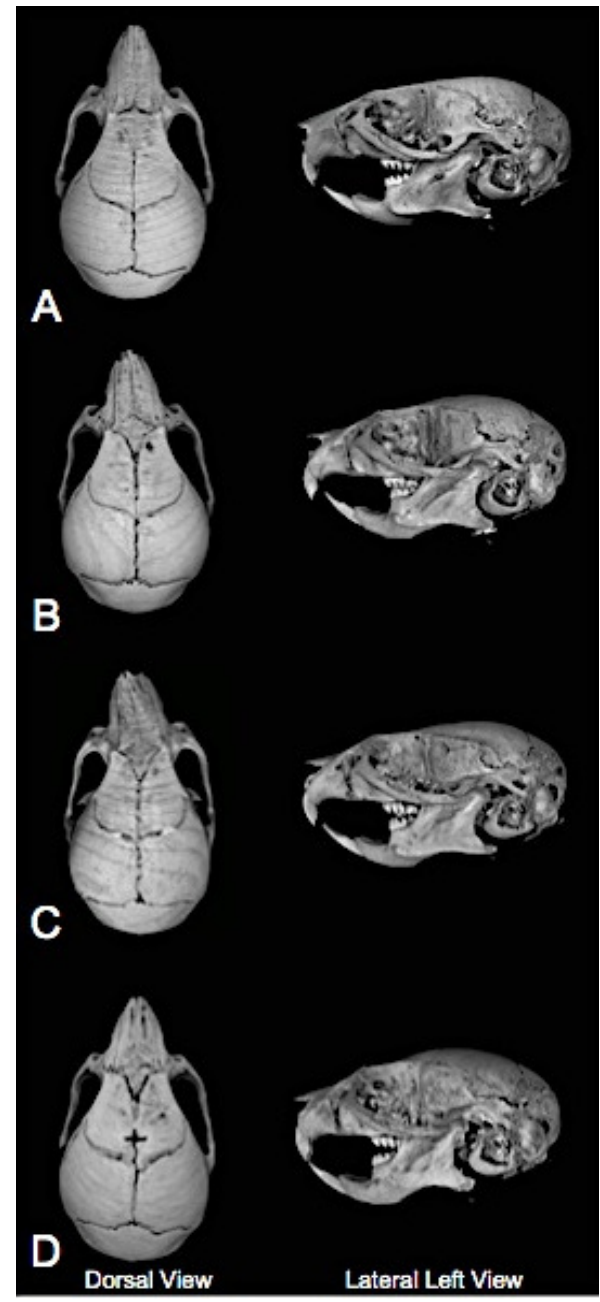

Figure 3: Qualitative variation in Sofa mutants. Dorsal and lateral views of the 3D reconstructions of the skulls of 4 mice. Different phenotypic variations ranging from mild shortened face to more severe form. The incisors relationship is ranging from normal, edge-to-edge to anterior crossbite.

Volume 44 - Decem6er 2013 
Besides the midface hypoplasia, premature synostosis of the premaxillary-frontal suture is a consistent characteristic in Sofa mice. The synostosis is associated with fusion between the nasal bones and the interfrontal bone. This results in a striking delta or triangular shaped interfrontal bone. The heterozygotes also frequently exhibit a butterfly shaped gap in the posterior frontal suture. (Fig.4)

In some mutants, the midface hypoplasia with normal overjet mild although, they still typically exhibit the same pattern of premaxillary-frontal and posterior frontal suture anomalies, partial ossification of the intersphenoidal synchondrosis located and occasional snout deviation.

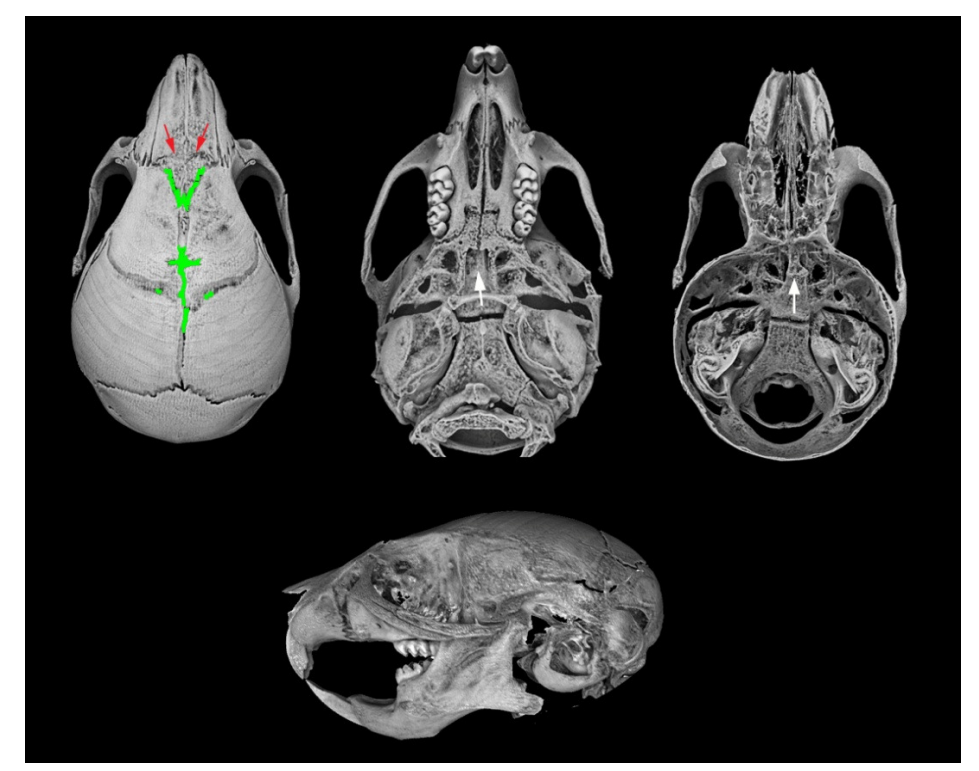

Figure 4: Severe presentation associated with the Sofa mutation. Indorsal view, cranial base view,neurocranium, and lateral view. Midface is deficient associated with edge-toedge relationship. Premaxillary-frontal suture is partially synostotic (red arrows) with sagittal suture performing delta pattern around the interfrontal bone, and butterfly defect in the posterior frontal and interfrontal sutures (green highlighting). Ossification between presphenoid and basisphenoid bones (white arrows). 
Egyptian

Orthodontic Journal

\section{DISCUSSION}

Amusing progress has been achieved recently to identify the possible genetic background of different dental as well as skeletal malocclusions. Class III malocclusion is considered to be one of the challenging forms of malocclusions that face orthodontists in the daily practice. However, several projects are still trying to correlate between the phenotype and genotype in class III malocclusion due to its different etiological factors.

This study aimed to characterize the craniofacial skeletal morphology of new mouse mutant associated with midface hypoplasia, and to establish genotype-phenotype correlation that may help introducing this mutant as a model of class III malocclusion.

The Sofa mutants in this study had varied penetrance ranging from an obvious to a subtler short nose phenotype. The variation in penetrance affected the expression of midfacial hypoplasia (Fig.3). The severe deficiency in midface could be related to two main causes: First, the premature synostosis between nasal bones and interfrontal bone (Fig.4). Second, the premature ossification of the intersphenoidal and interoccipital synchondroses was common in severely affected mutants (Fig.4). In addition, these mice carried a characteristic butterfly shaped gap in the sagittal suture close to the coronal suture (Fig.4).

The deficiency in the midface of Sofa mutants appears to be a common feature. Mutants shared characteristic features regarding the aberration in cranial sutures (premature fusion of pre-maxillary frontal suture), premature ossification of basicranium synchondroses, and the butterfly gap along the posterior frontal suture. Sofa mutation is expressing the same phenotype described by Chen et al $(2003)^{10}$ and Purushothaman et al $(2011)^{11}$ in Fgfr1 and Fgfr2 mouse models. However, the premature fusion of synchondroses remains a unique feature in the new line.

In conclusion, this study demonstrates that the Sofa mouse mutants are characterized by the presence of midface deficiency and may act as future model of class III malocclusion. Further studies are needed to illustrate the causative gene behind this phenotype and the type of the characteristic mutation that demonstrated this phenotype. 
Egyptian

Orthodontic Journal

\section{REFERENCES}

1- Ellis E, McNamara JA. Components of adult Class III open-bite malocclusion. Am J Orthod.1984;86:277-90.

2- Guyer EC, Ellis EE, McNamara JA, Behrents RG. Components of class III malocclusion in juveniles and adolescents. Angle Orthod 1986;56:7-30.

3- Delaire J. Mandibularprognathic syndrome. Orthod Fr 1976;47:203-19.

4- Gu Y, Zhang Y, Zhao C, Pan Y, Smales R, Wang H et al. Serum microRNAs as potential biomarkers of mandibular porgnathism. Oral Dis 2013:doi:10.1111.

5- Tassopoulou-Fishell M, Deeley K, Harvey EM, Sociote J, Vieira AR. Genetic variation in myosin $1 \mathrm{H}$ contributes to mandibular prognathism. Am J Orthod Dentofacial Orthop 2012;141:51-9.

6- McNamara JA. Maxillary transverse deficiency. Am J Orthod Dentofacial Orthop 2000;117:567-70.

7- Boyadjiev SA. Genetic analysis of non-syndromic craniosynostosis. Orthod Craniofacial Res 2007;10:129-37.

8- Wilkie AO, Byren JC, Hurst JA, Jayamohan J, Johnson D, Knight SJ et al. Prevalence and complications of single gene and chromosomal disorders in craniosynostosis. Pediatrics 2010;126:e391-e400.

9- Kaminen-Ahola N, Ahola A, Maga M, Mallitt K, Fahey A, Cox TC, et al. Maternal Ethanol Consumption Alters the Epigenotype and the Phenotype of Offspring in a Mouse Model. PLoS Genet 2010;1(6): e1000811. doi:10.1371/journal.pgen.1000811.

10- Chen L, Li D, Li C, Engel A, Deng C. A Ser250Trp substitution in mouse fibroblast growth factor receptor 2 (Fgfr2) results in craniosynostosis. Bone 2003;33:169-78.

11- Purushothaman R, Cox TC, Maga AM, Cunningham ML. Facial suture synostosis of newborn Fgfr1P250R/+ and Fgfr2S252W/+ mouse models of Pfeiffer and Apert syndromes. Birth Def Res 2011;91:603-9. 